\title{
Quantitative immunogold ultracryomicrotome studies of the distribution of periimplantation proteins in the sheep
}

F.B.P. Wooding ${ }^{1}$, G. Morgan ${ }^{1}$, and R.M. Roberts ${ }^{2}$

1 AFRC Institute of Animal Physiology and Genetics Research, Babraham, Cambridge CB2 4AT, UK

${ }^{2}$ Department of Animal Science, University of Missouri, Columbia, MS 65211, USA

Cell Tissue Res (1991) 265:83-93

In Table 1 on p. 84 of the above article, the column "Uninucleate chorion" should have been "Uterine epithelium." The entire table is reprinted below.

Table 1. Intensity of immunogold labelling for OTP-1 (gold particles $/ \mu \mathrm{m}^{2}$ ) over the various tissues and organelles on ultrathin frozen sections of sheep conceptuses and uterine epithelium

\begin{tabular}{|c|c|c|c|c|c|c|c|c|}
\hline $\begin{array}{l}14 \mathrm{dpc} \\
\text { caruncle }\end{array}$ & $\begin{array}{l}15 \mathrm{dpc} \\
\text { caruncle }\end{array}$ & $\begin{array}{l}16 \mathrm{dpc} \\
\text { caruncle }\end{array}$ & $\begin{array}{l}17 \mathrm{dpc} \\
\text { caruncle }\end{array}$ & $\begin{array}{l}19 \mathrm{dpc} \\
\text { caruncle }\end{array}$ & $\begin{array}{l}24 \mathrm{dpc} \\
\text { caruncle }\end{array}$ & $\begin{array}{l}41 \mathrm{dpc} \\
\text { caruncle }\end{array}$ & $\begin{array}{l}41 \mathrm{dpc} \\
\text { inter- } \\
\text { caruncle }\end{array}$ & $\begin{array}{l}14 \mathrm{dpc} \text { caruncle } \\
\text { absorbed } \\
\text { control }\end{array}$ \\
\hline
\end{tabular}

\begin{tabular}{|c|c|c|c|c|c|c|c|c|}
\hline \multicolumn{9}{|c|}{ Uninucleate chorion } \\
\hline Crystal & $18 \pm 3(31)$ & $20 \pm 2(15)$ & $29 \pm 3(35)$ & $13 \pm 1(54)$ & $24 \pm 2(24)$ & $8 \pm 1(14)$ & None found $16 \pm 2(15)$ & $23 \pm 2(12)$ \\
\hline Cytoplasm & $4 \pm 0.5(56)$ & $3 \pm 0.5(30)$ & $8 \pm 1(58)$ & $1 \pm 0.5(63)$ & $1 \pm 0.5(34)$ & $1 \pm 0.5(17)$ & $1 \pm 0.5(17) \quad 1 \pm 0.5(11)$ & $1 \pm 0.5$ \\
\hline Nuclei & $1 \pm 0.5(25)$ & $1 \pm 0.5(25)$ & $3 \pm 0.5(50)$ & $1 \pm 0.5(57)$ & $1 \pm 0.5(45)$ & $2 \pm 0.5(17)$ & $1 \pm 0.5(16)$ & $1 \pm 0.5(17)$ \\
\hline Golgi & $62 \pm 4(31)$ & $30 \pm 2(17)$ & $48 \pm 3(37)$ & $4 \pm 1(81)$ & $2 \pm 0.5(40)$ & $1 \pm 0.5(13)$ & $1 \pm 0.5(16) \quad 1 \pm 0.5(13)$ & $3 \pm 0.5(13)$ \\
\hline
\end{tabular}

Binucleate chorion

Uterine epithelium

Crystal

Syncytium

$$
\text { All areas }<1 \text { except } 17 \text { dpc: crystal: } 9 \pm 1 \text { (41) }
$$

Cytoplasm, nuclei, Golgi all $<2$

$$
9 \pm 1(10) \quad 9 \pm 1(27) \quad 7 \pm 1(15)
$$

None present before $19 \mathrm{dpc}$ after which syncytium, cytoplasm, nuclei, Golgi all <2 but crystal: $\quad 20 \pm 1(15) \quad 12 \pm 2(15)$ Allantois cytoplasm, nuclei, Golgi all $<1$

Frequencies are given mean $\pm S E M$, numbers in brackets indicate the number of $1 \mu \mathrm{m}^{2}$ areas counted 